\title{
Gallium gradients in chalcopyrite thin films: Depth profile analyses of films grown at different temperatures
}

\author{
H. Mönig ${ }^{1,2, a)}$ C. A. Kaufmann, ${ }^{2}$ Ch.-H. Fischer, ${ }^{2,3}$ A. Grimm, ${ }^{2}$ R. Caballero, ${ }^{2,4}$ B. Johnson, ${ }^{2}$ \\ A. Eicke, ${ }^{5}$ M. Ch. Lux-Steiner, ${ }^{2,3}$ and I. Lauermann ${ }^{2}$ \\ ${ }^{1}$ Center for Research on Interface Structures and Phenomena, Yale University, New Haven, \\ Connecticut 06511, USA \\ ${ }^{2}$ Helmholtz-Zentrum Berlin für Materialien und Energie, Hahn-Meitner-Platz 1, 14109 Berlin, Germany \\ ${ }^{3}$ Freie Universität Berlin, 14109 Berlin, Germany \\ ${ }^{4}$ Departamento de Física Aplicada, Universidad Autónoma de Madrid, Módulo 12, 28049 Madrid, Spain \\ ${ }^{5}$ Zentrum für Sonnenenergie- \& Wasserstoff-Forschung, 70565 Stuttgart, Germany
}

(Received 18 June 2011; accepted 24 September 2011; published online 7 November 2011)

\begin{abstract}
$\mathrm{Cu}(\mathrm{In}, \mathrm{Ga}) \mathrm{Se}_{2}$ films are used as absorber layers in chalcopyrite thin film solar cells. As the gallium concentration in the absorber can be used to control the band gap, there have been many efforts to vary the gallium concentration in depth to gain an optimum balance of light absorption, carrier collection, and recombination at different depths of the absorber film, leading to improved quantum efficiency. In this study, we investigate the effect of the maximum substrate temperature during film growth on the depth dependent gallium concentration. For the in-depth gallium concentration analyses, we use two techniques, covering complementary depth ranges. Angle dependent soft x-ray emission spectroscopy provides access to information depths between 20 and $470 \mathrm{~nm}$, which covers the depth range of the space charge region, where most of the photoexcited carriers are generated. Therefore, this depth range is of particular interest. To complement this investigation we use secondary neutral mass spectrometry, which destructively probes the whole thickness of the absorber $(\approx 2 \mu \mathrm{m})$. The two methods show increasingly pronounced gallium and indium gradients with decreasing maximum substrate temperature. The probing of the complementary depth ranges of the absorbers gives a consistent picture of the in-depth gallium distribution, which provides a solid basis for a comprehensive discussion about the effect of a reduced substrate temperature on the formation of gallium gradients in $\mathrm{Cu}(\mathrm{In}, \mathrm{Ga}) \mathrm{Se}_{2}$ and the device performance of the corresponding reference solar cells. (C) 2011 American Institute of Physics. [doi:10.1063/1.3656986]
\end{abstract}

\section{INTRODUCTION}

$\mathrm{Cu}(\mathrm{In}, \mathrm{Ga}) \mathrm{Se}_{2}$ thin films are widely used as absorber layers in chalcopyrite thin film solar cells. Record cells with a standard device structure glass $/ \mathrm{Mo} / \mathrm{Cu}(\mathrm{In}, \mathrm{Ga}) \mathrm{Se}_{2} / \mathrm{CdS} / \mathrm{ZnO}$ have recently achieved a remarkable conversion efficiency of $20.3 \%{ }^{1}$ The material properties of the roughly $2 \mu \mathrm{m}$ thick $\mathrm{Cu}(\mathrm{In}, \mathrm{Ga}) \mathrm{Se}_{2}$ chalcopyrite thin film determine the optoelectronic properties of the devices to a large extent. Especially, the gallium content $g g i=[G a] /([G a]+[I n])$ can be used to adjust the band gap of the material from $1.0 \mathrm{eV}$ to $1.7 \mathrm{eV}$ within a range of $g g i=0$ and $g g i=1$, respectively. This increase of the band gap affects for the most part the position of the conduction band minimum and only to a minor degree the valence band maximum. ${ }^{2,3}$ The control of the band gap and band edge positions in the semiconductor via its gallium content, offers possibilities to optimize the photovoltaic performance of the solar cells. Thereby, the optimization is not limited to the overall band gap and gallium content within the film. It is, for example, possible to engineer the energy level alignment at the crucial interface between the p-type absorber and the n-type window layer by adjusting the gallium content at the surface of the absorber., ${ }^{3,4}$ By establishing a gal-

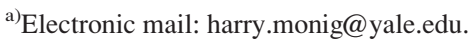

lium gradient, it is furthermore possible to balance absorption and carrier recombination within the space charge region (front grading). In addition, an increasing gallium content towards the molybdenum back contact is expected to enhance carrier collection and to decrease recombination via asymmetric diffusion, repelling electrons from the $\mathrm{Cu}(\mathrm{In}, \mathrm{Ga}) \mathrm{Se}_{2} / \mathrm{Mo}$ interface.$^{5-10}$ The combination of a gallium grading towards the front and the back interfaces is commonly referred to as double grading. In general, a double grading within a $\mathrm{Cu}(\mathrm{In}$, $\mathrm{Ga}) \mathrm{Se}_{2}$ thin film can be achieved via the standard three-stage co-evaporation growth process. ${ }^{5,8}$ However, a compositional grading can also be unfavorable for the device performance, which holds in particular within the space charge region. ${ }^{7,11}$ Therefore a detailed knowledge of the gallium depth profile is highly desirable. Recent studies by D. Abou-Ras et al. ${ }^{12}$ and C. L. Perkins ${ }^{13}$ emphasize the necessity for comparative investigations of elemental depth profiles by different analytical tools to achieve reliable results.

It is known that the substrate temperature during film growth affects the gallium depth profiles in $\mathrm{Cu}(\mathrm{In}, \mathrm{Ga}) \mathrm{Se}_{2}$ thin films grown in the three-stage process. ${ }^{14,15}$ Moreover, the maximum process temperature during film growth is a critical parameter when flexible substrates, as for example polyimide foil, are used. Kaufmann et al. ${ }^{14}$ investigated the effect of reduced maximum process temperatures on the 
material properties of $\mathrm{Cu}(\mathrm{In}, \mathrm{Ga}) \mathrm{Se}_{2}$ thin films grown on float glass substrates. A distinct effect of the maximum process temperature on the gallium depth profile was found by crosssectional energy-dispersive $\mathrm{x}$-ray spectroscopy (EDX). The $\approx 2 \mu \mathrm{m}$ thick absorbers were investigated by recording EDX line scans along the device cross-sections, which, under optimum conditions, show a maximum resolution of $120-150 \mathrm{~nm} .{ }^{16}$ To get more detailed information about gallium depth profiles at reduced maximum growth temperatures, the present paper reports on comprehensive depth profile analyses of absorber layers grown at three different maximum process temperatures. For the investigations, we use two methods, covering different depth ranges of the absorber. Synchrotron based angle dependent soft x-ray emission spectroscopy (AXES) non-destructively probes the depth dependent composition, while covering information depths between 20 and $470 \mathrm{~nm}$. Thus, AXES provides information about the depth dependent gallium content in a depth range of the space charge region, which extends only a few hundred nanometers into the bulk. ${ }^{9,17}$ In this depth range, most of the photoexcited carriers are generated and spatially separated under solar cell operation. Therefore, compositional gallium gradients are here of particular interest. The second method is secondary neutral mass spectrometry (SNMS), which is a destructive technique, where the material is successively removed to identify the constituent elements from a certain depth in a mass spectrometer. Thereby, SNMS covers the whole depth range of the $\mathrm{Cu}(\mathrm{In}, \mathrm{Ga}) \mathrm{Se}_{2}$ thin films. With our comparative investigation, we achieve a comprehensive picture of the impact of the substrate temperature on the depth dependent gallium distribution in samples grown by the three-stage co-evaporation process.

\section{METHODS AND EXPERIMENTAL DETAILS}

\section{A. AXES experiments}

In our AXES experiments, the angle between the exciting monochromatic synchrotron beam and the spectrometer is fixed at $90^{\circ}$. The sample can be rotated with respect to this arrangement. Considering this geometry, the emitted differential intensity $d I^{\mathrm{E}}(x)$ from a volume element between $x$ and $x+d x$ of an emission line at energy $E$ from a certain depth $x$ of a specimen $s$ is given by ${ }^{18-20}$

$$
\begin{aligned}
d I^{\mathrm{E}}(\beta)= & I_{0} \mathrm{Q}_{\mathrm{E}} C_{\mathrm{i}}(x) \frac{d \Omega}{4 \pi} \frac{\rho(x)}{\cos \beta} \\
& \times \exp \left[-x \rho(x)\left(\frac{\mu_{\mathrm{Eo}}^{\mathrm{s}}(x)}{\cos \beta}+\frac{\mu_{\mathrm{E}}^{\mathrm{s}}(x)}{\sin \beta}\right)\right] d x .
\end{aligned}
$$

Here, $I_{0}$ is the intensity of the exciting synchrotron beam with an energy $E_{0}, \mathrm{Q}_{\mathrm{E}}$ the sensitivity factor of the spectrometer for a certain X-ray energy $E, d \Omega$ is the solid angle of the detected signal, $C_{\mathrm{i}}(x)$ is the concentration of an element $i$ in a certain depth $x, \beta$ is the angle between the sample surface and the spectrometer (exit angle), $\rho(x)$ is the density and $\mu_{\mathrm{Eo}}^{\mathrm{s}}(x)$ and $\mu_{\mathrm{E}}^{\mathrm{s}}(x)$ are the mass absorption coefficients of a specimen $s$ for the incident and emitted radiation, respectively. In the present work, we investigate gallium gradients, which requires that the elemental concentrations, the absorp- tion coefficients, and the density need to be considered as functions of the sample depth. The density as a function of the gallium content in the $\mathrm{Cu}(\mathrm{In}, \mathrm{Ga}) \mathrm{Se}_{2}$ thin films has been calculated following Ref. 21, where the lattice distortion due to the integration of gallium in the chalcopyrite matrix is included. The absorption coefficients at a certain x-ray energy and sample depth for our study are calculated by

$$
\mu^{\mathrm{s}}(x)=\rho^{\mathrm{s}}(x) \sum_{\mathrm{i}} \mathrm{G}_{\mathrm{i}}(x) \frac{\mu^{\mathrm{i}}(x)}{\rho^{\mathrm{i}}(x)},
$$

where $G_{i}(x)$ is the proportion of weight of an element $i, \mu^{i}(x)$ the elemental absorption coefficient, and $\rho^{i}(x)$ the elemental density. The elemental absorption coefficients and densities have been taken from Ref. 22.

In X-ray emission spectroscopy, the information depth can be defined as the depth normal to the surface, from which $95 \%$ of the detected signal originates. ${ }^{23}$ With this, the information depth $I D_{\text {XES }}$ can be deduced from Eq. (1), which results in (see Ref. 19),

$$
I D_{\mathrm{XES}}=-\ln (0.05)\left(\rho\left(\mu_{\mathrm{Eo}}^{\mathrm{s}}(x) / \cos \beta+\mu_{\mathrm{E}}^{\mathrm{s}}(x) / \sin \beta\right)\right)^{-1} .
$$

Assuming a $\mathrm{Cu}(\mathrm{In}, \mathrm{Ga}) \mathrm{Se}_{2}$ absorber material with a homogeneous elemental distribution of all elements and a copper content of $c g i=[\mathrm{Cu}] /([G a]+[\operatorname{In}])=0.85$ and a gallium content of $g g i=0.30, I D_{\mathrm{XES}}$ can be plotted as a function of the exit angle $\beta$. This plot is shown in Fig. 1 for the Ga $\mathrm{L}_{3} \mathrm{M}_{4,5}(h \nu=1097.9 \mathrm{eV})$ emission. A decrease in information depth can be observed towards grazing exit geometry $\beta$ $\rightarrow 0^{\circ}$, where the emitted radiation is progressively attenuated by the increasing exit path length. Similarly, towards grazing incident geometry $\beta \rightarrow 90^{\circ}$, a decrease in information depth can be achieved due to an increasing path length of the incident synchrotron beam, which leads to a limited penetration of the exciting radiation perpendicular to the sample surface. A maximum information depth of $\approx 470 \mathrm{~nm}$ is achieved at intermediate angles.

It should be emphasized that the information depth must be regarded as an estimate for the probing depth. A measured signal at a certain information depth cannot be regarded as the signal from this particular depth. Rather, the exponential damping of the exciting and emitted radiation (Eq. (1)) leads to a convolution of the depth dependent concentration $C_{\mathrm{i}}(x)$

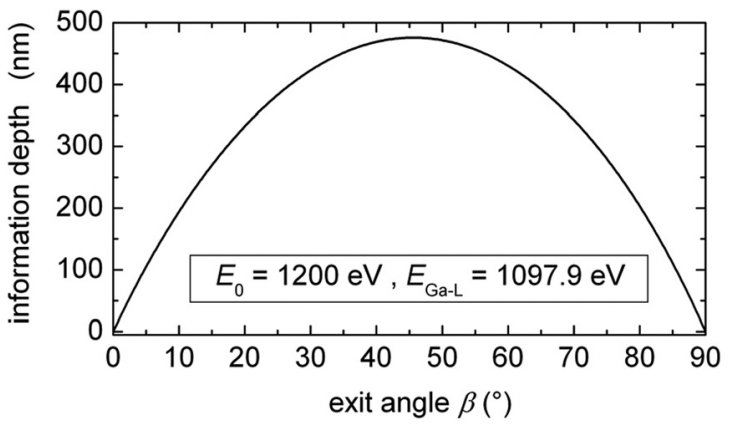

FIG. 1. AXES information depth as a function of the exit angle $\beta$, calculated for the $\mathrm{Ga}_{3} \mathrm{M}_{4,5}$ emission line for $\mathrm{Cu}(\mathrm{In}, \mathrm{Ga}) \mathrm{Se}_{2}(\operatorname{cg} i=0.85$ and $g g i=0.3)$ on the basis of Eq. (3). In agreement with our experiments, an excitation energy of $E_{0}=1200 \mathrm{eV}$ was assumed. 
and the material inherent absorption. Therefore, model calculations based on Eq. (1) are utilized to extract the information related to elemental gradients.

Experimental details: The AXES experiments were performed at the U 41 PGM beamline at the BESSY synchrotron facility using a soft $\mathrm{x}$-ray grating spectrometer ${ }^{24}$ under ultra high vacuum conditions. The spectrometer settings were adjusted to cover the two emission lines $\mathrm{Cu} \mathrm{L}_{3} \mathrm{M}_{4,5}$ $(h \nu=929.7 \mathrm{eV})$ and $\mathrm{Ga} \mathrm{L}_{3} \mathrm{M}_{4,5}(h \nu=1097.9 \mathrm{eV})$ in the same energy window. Note that the photon energies of these two emission lines are associated with similar absorption coefficients in $\mathrm{Cu}(\mathrm{In}, \mathrm{Ga}) \mathrm{Se}_{2}$, which means that the signal originates from the same depth in the sample. Using a constant excitation energy of $1200 \mathrm{eV}$, the spectra were recorded in second diffraction order of a grating with the specifications: grating curve radius $5 \mathrm{~m}$, blaze angle $0.8506^{\circ}$, incident angle $2.6^{\circ}$, and line distance $2.51 \mu \mathrm{m}$. The sample manipulator of the experimental setup allowed angle variations in steps of $0.5^{\circ}$. To calibrate the angular scale, we determined the grazing incident case for each sample by observing the extension of the synchrotron beam spot on the samples with an infrared camera. With this we achieved an accuracy of this calibration, which is limited by the step size of the angle adjustment and thus can be specified with $\pm 0.5^{\circ}$. The experimental data are presented in form of the intensity ratio of the copper and gallium emission lines as a function of the exit angle: $I^{\mathrm{Cu}}(\beta) / I^{\mathrm{Ga}}(\beta)$. The presented AXES data cover angles between $\beta=89.0^{\circ}$ and $\beta=45.0^{\circ}$, which correspond to information depths of 20 and $470 \mathrm{~nm}$, respectively.

As it will be discussed in more detail in the sample preparation section, the chalcopyrite absorber films for high efficiency solar cell applications are grown with a copper poor integral composition. With respect to this bulk composition, the surface of the absorber is even more copper depleted. In agreement with results from epitaxially grown $\mathrm{CuInSe}_{2}$ in Refs. 25 and 26, our previous studies by AXES and hard $\mathrm{x}$ ray photoelectron spectroscopy consistently provided strong experimental evidence that this surface copper depletion of polycrystalline $\mathrm{Cu}(\mathrm{In}, \mathrm{Ga}) \mathrm{Se}_{2}$ thin films is limited to an extremely thin and completely copper depleted surface layer. $^{20,27}$ This result supports first-principle calculations that predict a defect-induced surface reconstruction, explaining the unusual high stability of polar facets at chalcopyrite surfaces, where massive removal of surface copper from the top atomic layer compensates the charge imbalance of the dipoles. ${ }^{28}$ Due to the limited sensitivity, such a thin surface layer is not accessible by AXES. In fact we found that in the depth range probed by AXES, the copper concentration can be used as a reference for the depth dependent gallium content. A detailed discussion about this topic can be found in Ref. 20.

Possible effects due to the surface roughness of the $\mathrm{Cu}(\mathrm{In}, \mathrm{Ga}) \mathrm{Se}_{2}$ films on the AXES measurements were investigated in detail. ${ }^{19,20} \mathrm{We}$ found that it has only a small impact on our AXES measurements, which can be attributed to two major points: (i) the roughness of the films is mainly related to differences in height at grain boundaries, while on the grains there are large flat areas; (ii) as we evaluate exclusively relative emission intensities of energies with very similar absorption coefficients, the effect of the surface roughness on the copper and gallium $\mathrm{x}$-ray intensities is equal and showed to have only a minor impact on the results.

\section{B. SNMS experiments}

In SNMS, a sample is destructively analyzed by layer-bylayer removal of the material. An ion beam successively erodes the material, while the ejected neutral atoms are postionized and analyzed in a mass spectrometer. Our SNMS investigations were carried out in a LEYBOLD LHS10 instrument with a secondary neutral and ion mass spectrometer module (SSM 200) using a Balzers 511 quadrupole for mass separation. For sputter erosion the samples are bombarded by a focused $5 \mathrm{keV} \mathrm{Ar}{ }^{+}$ion beam under an angle of $60^{\circ}$ to the surface normal. The ion beam with a FWHM of about $100 \mu \mathrm{m}$ was scanned over an area of $3 \times 2 \mathrm{~mm}^{2}$. Neutral atoms and molecules are post-ionized in the lens system of the SSM 200 module by an electron beam of $70 \mathrm{eV}$ at a distance of about $2.5 \mathrm{~cm}$ from the sputtered area. Subsequently, the resulting ions are transmitted through ion optics, into the mass filter and detected as single ions by an electron multiplier. Note that secondary ions from the sample and residual gas ions are suppressed by the ion optics system. To increase the depth resolution of the measurement, sputtered neutral particles from the crater walls are suppressed by electronic gating, where the detection system is only activated when the ion beam hits a defined area in the center of the sputter crater. For the presented depth profiles, sputtered particles were detected only from an inner area of $(1.8 \times 1.2) \mathrm{mm}^{2}$, which represents $36 \%$ of the sputtered area. Due to the high sputter cross sections for neutral particles, the SNMS intensity profiles can be quantified. Sensitivity factors for the quantification of $\mathrm{Cu}(\mathrm{In}, \mathrm{Ga}) \mathrm{Se}_{2}$ elements by SNMS were determined by a calibration procedure, using cross-sectional energy-dispersive $\mathrm{x}$-ray spectroscopy and $\mathrm{x}$-ray fluorescence analysis. In order to compensate minor changes due to instrumental effects, each concentration profile of $\mathrm{Cu}(\mathrm{In}, \mathrm{Ga}) \mathrm{Se}_{2}$ is fitted to the overall layer concentration as measured with x-ray fluorescence. During $\mathrm{Ar}^{+}$etching, the samples are cooled with liquid nitrogen to prevent migration and clustering of surface atoms. Without cooling, these effects provoke a roughening of the sputtered surface and lead to a decreased depth resolution. Furthermore, this causes a distortion of the elemental depth profiles. Therefore, the cooling of the samples during the sputter process improves the precision of the SNMS depth profiles significantly. ${ }^{29}$

\section{Sample preparation}

The polycrystalline $\mathrm{Cu}(\mathrm{In}, \mathrm{Ga}) \mathrm{Se}_{2}$ thin films were grown on molybdenum coated float glass substrates, using a multistage co-evaporation process, which is based on the threestage process. ${ }^{30,31}$ This type of deposition process is diffusion limited as it largely relies on temperature induced elemental inter-diffusion. The timeline for the element specific deposition rates and substrate temperature during the process is schematically shown in Fig. 2. It is subdivided in three stages as specified at the top of Fig. 2. The substrate temperature during the first stage is $T_{1}$ and during the second and third stages $T_{2}$. The selenium flux is held constant at $\approx 12 \AA / \mathrm{s}$ for 


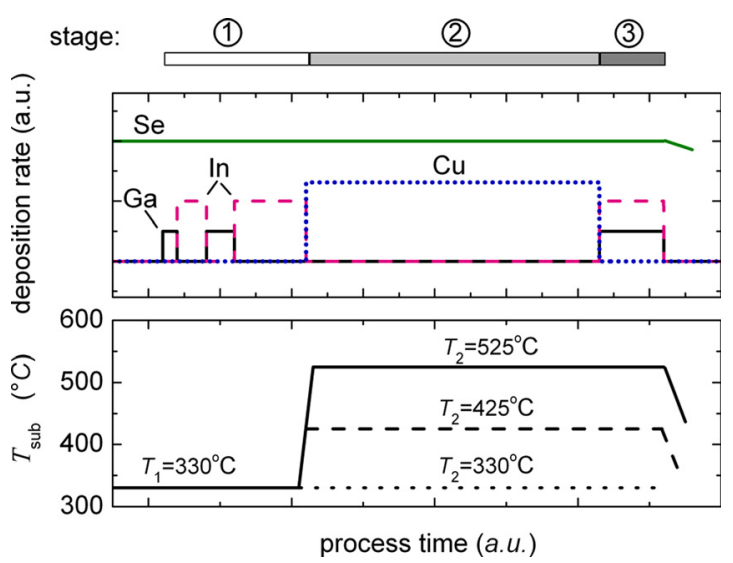

FIG. 2. (Color online) Schematic of the multi-stage co-evaporation process, displaying elemental deposition rates and substrate temperature during film growth.

all the processes. In the first stage the gallium and indium precursors are deposited sequentially. During the second stage, only copper and selenium are deposited. Initially, this leads to the formation of a copper-poor chalcopyrite phase and after surpassing the point of a stoichiometric composition, an intermediate segregation of copper selenides at the absorber surface. At the end of stage two, the targeted nominal composition of the deposited film in terms of copper content is $c g i=1.15$. In the third stage, solely gallium and indium are supplied to achieve a final integral copper composition within a range of $0.80 \leq c g i_{\text {int }} \leq 0.92$, which is mandatory for high efficiency solar cells. ${ }^{1}$ Process control is realized using laser light scattering (LLS) and pyrometry. ${ }^{32}$

The three chalcopyrite thin films for the present study were grown using a constant substrate temperature $T_{1}=330{ }^{\circ} \mathrm{C}$ and different $T_{2}$, which was set to $330{ }^{\circ} \mathrm{C}$, $425{ }^{\circ} \mathrm{C}$, and $525{ }^{\circ} \mathrm{C}$, in order to investigate the effect on the gallium distribution in depth. The integral copper and gallium contents from the three process runs were determined by x-ray fluorescence analysis and are shown in Table I together with the process times used for the different stages. The targeted integral gallium content for the three films is $g g i_{\text {int }}=0.27$. Care was taken to terminate the growth for all the films by simultaneously closing the indium and the gallium shutters at the end of stage three.

As the growth process is diffusion limited, the copper flux during stage 2 had to be reduced for the lower process temperatures $T_{2}$ to prevent the early formation of copper selenides. While the presence of this copper-rich growth phase is required at some point during the deposition of a high quality absorber, ${ }^{33}$ care needs to be taken that the cop-

TABLE I. Growth process details: substrate temperature $T_{2}$, duration of the 2nd and 3rd deposition stages $\left(t_{2}, t_{3}\right)$, and the resulting integral copper and gallium contents $\left(c g i_{\text {int }}\right.$ and $\left.g g i_{\text {int }}\right)$ of the as-grown films as measured by $\mathrm{x}$-ray fluorescence analysis.

\begin{tabular}{lcccc}
\hline \hline$T_{2}\left({ }^{\circ} \mathrm{C}\right)$ & $t_{2}(\min )$ & $t_{3}(\min )$ & $g g i_{\text {int }}$ & $c g i_{\text {int }}$ \\
\hline 330 & 100 & 3.3 & 0.28 & 0.90 \\
425 & 58 & 3.9 & 0.30 & 0.89 \\
525 & 25 & 3.2 & 0.28 & 0.84 \\
\hline \hline
\end{tabular}

per selenides form only after the overall stoichiometry of the film becomes copper-rich, and not just at the surface near region. Therefore, the decreased copper flux with decreasing $T_{2}$ is reflected in the longer process time $t_{2}$ of the second stage of the growth process (see Table I). Note that the effect of different copper fluxes during low temperature multistage co-evaporation on the resulting device quality was recently investigated in more detail. ${ }^{34}$ The slight variation in the final integral copper content of the three sample materials (Table I) is most likely caused by a systematic error in the utilization of the process control LLS, which is based on the assumption of identical optical properties of the material. As discussed within the following section, this assumption is not strictly correct for our samples. Nevertheless LLS is judged a highly powerful tool for in-situ process control.

From each process run, we fabricated reference devices, which were completed by deposition of $\mathrm{CdS}$ in an aqueous chemical bath, $\mathrm{RF}$ sputtering of a $\mathrm{ZnO} / \mathrm{ZnO}$ : Al bilayer transparent front contact and evaporation of a $\mathrm{Ni} / \mathrm{Al}$ contact grid (total device area: $0.5 \mathrm{~cm}^{2}$ ). I-V measurements were performed using standard measurement conditions under AM1.5 illumination. The photoactive band gaps of the solar cell devices were determined via derivation of the external quantum efficiency (EQE).

To prevent that surface contaminations affect the measurements, the samples were treated in an aqueous KCN solution $(5 \%)$ for $3 \mathrm{~min}$ at room temperature prior to the measurement. After this $\mathrm{KCN}$ treatment the samples were rinsed extensively in purified water, dried in a flow of nitrogen, and immediately transferred into ultra high vacuum.

\section{RESULTS AND DISCUSSION}

Fig. 3 shows a comparison of the AXES and SNMS data of the three samples grown at the different substrate temperatures $T_{2}$. The AXES data in Figs. 3(a)-3(c) show an increasing angle dependence of the peak intensity ratio $I^{\mathrm{Cu}}(\beta) / I^{\mathrm{Ga}}(\beta)$ with decreasing substrate temperature. Note that for better comparability, the AXES data are all shown with the same scales. The SNMS depth profiles in Figs. 3(d)-3(f) show, consistent with AXES, an increasing inhomogeneous distribution of gallium and indium with sample depth. Due to the isovalent substitution of gallium and indium in the chalcopyrite matrix, the two elements show opposed depth profiles. The solid lines shown together with the AXES data are model calculations based on Eq. (1). For these calculations, we assumed the copper and gallium depth profiles $C_{\mathrm{Cu}}(x)$ and $C_{\mathrm{Ga}}(x)$ shown as dashed black lines in the SNMS data (Figs. 3(d)-(f)), which are shown up to $470 \mathrm{~nm}$ (the maximum information depth of AXES). Considering the related depth dependence of the mass absorption coefficients $\left(\mu_{\mathrm{Eo}}^{\mathrm{s}}(x), \mu_{\mathrm{E}}^{\mathrm{s}}(x)\right)$ and density $\rho(x)$, we numerically integrated Eq. (1) to gain $I^{\mathrm{Cu}}(\beta)$ and $I^{\mathrm{Ga}}(\beta)$ for a specific exit angle $(\beta)$. These integrations were performed for the whole range of exit angles with a step size of $\Delta \beta=0.01 \mathrm{rad} \approx 0.57^{\circ}$ to achieve a quasi-continuous function for $I^{\mathrm{Cu}}(\beta) / I^{\mathrm{Ga}}(\beta)$. The solid lines in Figs. 3(a)-3(c) were iteratively fitted to the experimental AXES data by variations of the corresponding concentration depth profiles $C_{\mathrm{Cu}}(x)$ and $C_{\mathrm{Ga}}(x)$. 

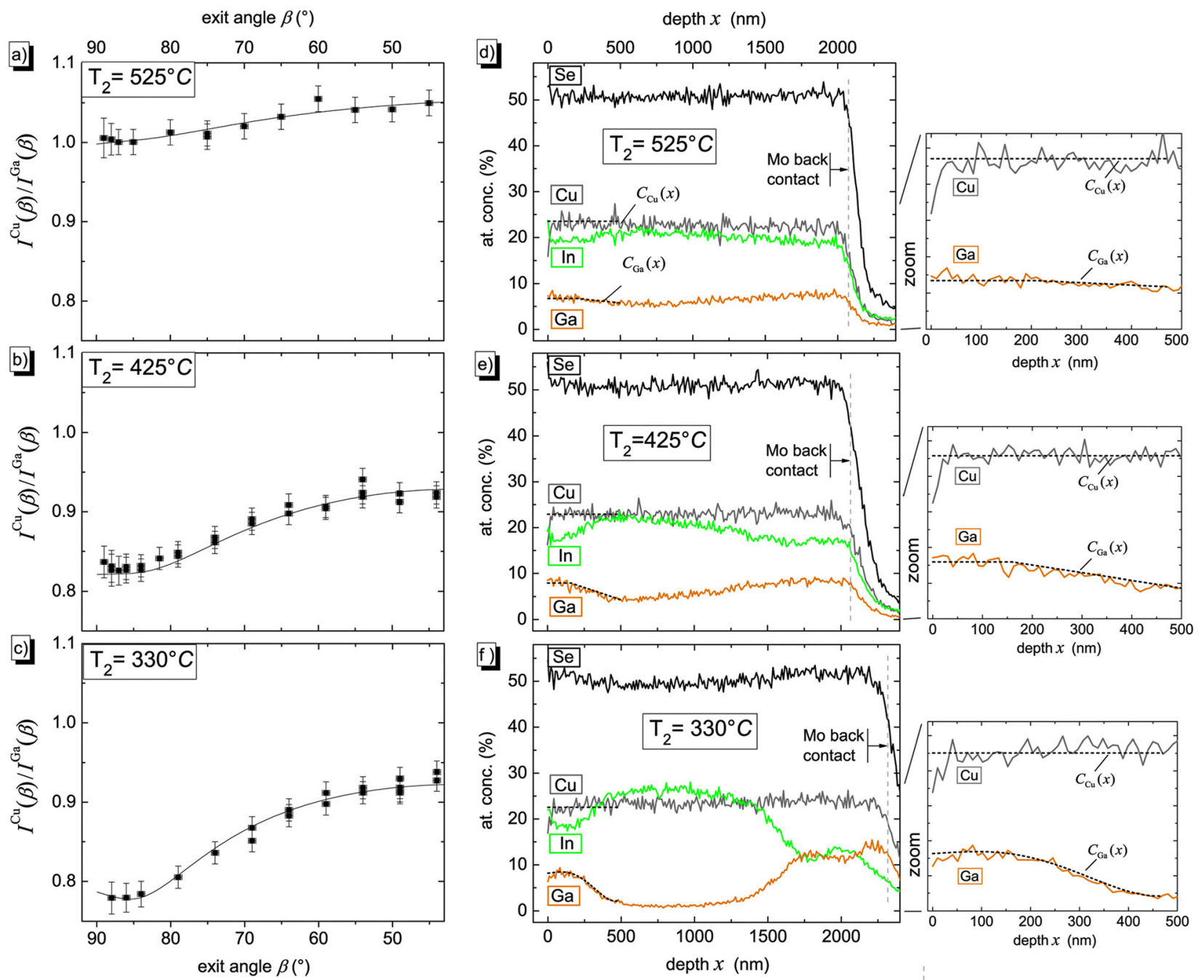

FIG. 3. (Color online) Comparison of the AXES and SNMS data for the three investigated samples. (a)-(c): AXES peak intensity ratio $I^{\mathrm{Cu}}(\beta) / I^{\mathrm{Ga}}(\beta)$ as a function of the exit angle $\beta$. The solid lines show model calculations based on Eq. (1) considering the copper and gallium concentration depth profiles $\left(C_{\mathrm{Cu}}(x)\right.$ and $C_{\mathrm{Ga}}(x)$ ) shown as black dashed lines in the SNMS data. (d)-(f): SNMS depth profiles (color coded) and depth profiles used for the AXES model calculations (black dashed lines at $x<500 \mathrm{~nm}$ ). On the very right, zoomed cut-outs are shown.

With decreasing maximum process temperature $T_{2}$, our AXES and SNMS results consistently show increasingly pronounced gallium and indium gradients through the absorber layer. Thereby, the model calculations for the nondestructive AXES measurements show remarkable agreement with the destructive SNMS measurements. Only the very first data points of the copper concentration in the SNMS depth profiles show deviations to lower values for all samples, which is most probably related to the copper depletion of chalcopyrite thin film surfaces with respect to their bulk composition. As mentioned above, it was found that this surface copper depletion is restricted to the top atomic layer and is caused by a defect-induced surface reconstruction, ${ }^{25-27}$ which is not accessible by AXES. ${ }^{20}$ The reduced copper concentration in the SNMS data could be a consequence of this. Considering the distance between the data points of $\approx 10 \mathrm{~nm}$, the first few SNMS points reflect averaged values for the copper concentration due to the extremely localized compositional deviation at the surface.

As the growth process is temperature induced, the increasingly pronounced gallium and indium gradients with decreasing substrate temperature can be attributed to the inhibited inter-diffusion, even though the process times were considerably longer with lower $T_{2}$ (see Table I). Comparing the process timeline in Fig. 2 with the SNMS depth profiles in Figs. 3(d)-3(f) shows that with decreasing $T_{2}$ the deposition rates from the process are increasingly reflected in the gallium and indium depth profiles. In particular, the sample with $T_{2}=330{ }^{\circ} \mathrm{C}$ shows an accumulation of gallium in the front $(x<500 \mathrm{~nm})$ and at the back $x>1500 \mathrm{~nm}$. Gallium/indium inter-diffusion can be assumed to be fast at a high deposition temperature $T_{2}$, i.e., a flat gallium gradient should be anticipated as soon as a substrate temperature of $525^{\circ} \mathrm{C}$ is reached. In this case the positive gallium gradient towards the back of devices is often attributed to a preferential out-diffusion of indium towards the absorber surface during stage 2 , while copper and selenium are evaporated onto the growing absorber layer. ${ }^{5}$ Further introduction of indium, gallium, and selenium during stage 3 of the deposition process results in the positive gallium gradient towards the surface. As the maximum deposition temperature is reduced, the reduction of the diffusion velocity of the different species within the growing film becomes more and more dominating. Hence, at the very low deposition temperature of $T_{2}=330^{\circ} \mathrm{C}$, the process 
sequence of the 1st stage of the deposition process is partly preserved in the gallium/indium depth profile. This shows that at low deposition temperatures the gallium gradient within the device can be controlled by the elemental deposition rates. ${ }^{15,35}$

A further possible influence on the gallium grading is the copper content of the final thin film. In principle, for multistage co-evaporation, a higher copper content should lead to a decrease of the gallium concentration at the absorber surface. ${ }^{36}$ In our case, however, the effect of the different temperatures dominates the growth kinetics, while the impact of the small variations in the integral copper content of our samples ( $c g i=0.84-0.90$, see Table I) on the gallium depth profiles can be regarded as minor.

It should be noted that the presence of sodium is another parameter, having an impact on the elemental interdiffusion. In standard high efficiency devices, sodium is supplied to the growing thin film via diffusion from the glass substrate through the molybdenum back contact. As the sodium diffusion is also temperature activated, there are different amounts of sodium present within the final absorber layer. It is found that this also affects the diffusion velocities of the different species within the growing films, ${ }^{37}$ which has to be considered for a comprehensive understanding of the gallium/indium inter-diffusion mechanisms.

It is assumed that an increase of the band gap (or gallium content, respectively) towards the front and towards the back of the absorber, both can improve the efficiency of the devices. However, the optimum grading parameters for such a double grading profile (slopes and location of the minimum) are still under discussion. ${ }^{8,9}$ Especially the grading parameters within the space charge region (towards the front) seem to be critical. ${ }^{7,8,11}$ Thereby, the extension in depth of the space charge region in $\mathrm{Cu}(\mathrm{In}, \mathrm{Ga}) \mathrm{Se}_{2}$ absorbers lies in a depth range of a few hundred nanometers,${ }^{9,17}$ where under solar cell operation, most of the photoexcited carriers are generated.

Table II shows the characteristic PV parameters of devices made from absorber layers that have been deposited in the same deposition runs as the samples for the depth profile analyses. The photoactive band gap, $E_{g}^{\text {active }}$, clearly decreases with the maximum process temperature, although the integral gallium content for the three processes is similar (Table I). A simultaneous increase of $j_{s c}$ confirms this trend. The reason for this is the minimum gallium content that can be seen to vary in the SNMS depth profiles in Fig. 3. It seems that at $T_{2}=330^{\circ} \mathrm{C}$ a region with very little or no gallium is

TABLE II. $\mathrm{Cu}(\mathrm{In}, \mathrm{Ga}) \mathrm{Se}_{2}$ device performance and photoactive band gap. The PV-parameters are averaged over a minimum of 21 devices. The devices are fabricated with absorbers from the same deposition run as those absorbers investigated above. $E_{g}^{a c t i v e}$ is determined via derivation of the EQE.

\begin{tabular}{lcccccc}
\hline \hline$T_{2}\left({ }^{\circ} \mathrm{C}\right)$ & $E_{g}^{\text {active }} \mathrm{eV}$ & $g g i_{\text {int }}$ & $V_{o c}(\mathrm{mV})$ & $j_{s c}(\mathrm{~mA} / \mathrm{cm} 2)$ & $F F(\%)$ & $\eta(\%)$ \\
\hline 330 & 1.03 & 0.28 & $517 \pm 5$ & $39.1 \pm 0.8$ & $54.3 \pm 2.4$ & $11.0 \pm 0.5$ \\
425 & 1.09 & 0.30 & $571 \pm 12$ & $35.6 \pm 0.4$ & $67.5 \pm 1.9$ & $13.7 \pm 0.6$ \\
525 & 1.15 & 0.28 & $632 \pm 9$ & $32.9 \pm 0.6$ & $75.9 \pm 4.0$ & $15.8 \pm 1.1$ \\
\hline \hline
\end{tabular}

incorporated into the $\mathrm{Cu}(\mathrm{In}, \mathrm{Ga}) \mathrm{Se}_{2}$ thin film. Interestingly $\Delta E_{g}^{\text {active }}$ correlates well with the loss observed in $V_{o c}$. Regarding the fill factor $F F$, the gallium gradient in the surface near region is most likely the restrictive factor.

\section{CONCLUSIONS}

Our study provides a detailed knowledge of the effects of the substrate temperature on the depth dependent gallium content with a particular emphasis on the depth range of the space charge region in $\mathrm{Cu}(\mathrm{In}, \mathrm{Ga}) \mathrm{Se}_{2}$ thin films. The substrate temperature during the growth of the absorber films is a promising potential parameter to gain control over the depth dependent gallium distribution and related band gap profile. Combining variations of the evaporation profile with variations of the substrate temperature during the three stage process could be an effective approach to test and optimize the influence of band gap profiles in chalcopyrite absorbers. Our comparative depth profile analyses by AXES and SNMS provide a consistent and conclusive picture of the in-depth gallium distribution for the investigated samples.

\section{ACKNOWLEDGMENTS}

The authors acknowledge the support of the European Commission in the framework of the ATHLET-project (Project No. 019670). We would like to thank P. Körber, T. Kropp, and the BESSY staff (especially Ch. Jung, and M. Mast) for technical support.

${ }^{1}$ P. Jackson, D. Hariskos, E. Lotter, S. Paetel, R. Würz, R. Menner, W. Wischmann, and M. Powalla, Prog. Photovoltaics 19, 894 (2011).

${ }^{2}$ S.-H. Wei, S. B. Zhang, and A. Zunger, Appl. Phys. Lett. 72, 3199 (1998).

${ }^{3}$ M. Turcu, I. M. Kötschau, and U. Rau, J. Appl. Phys. 91, 1319 (2002).

${ }^{4}$ T. Schulmeyer, R. Kniese, R. Hunger, W. Jaegermann, M. Powalla, and A. Klein, Thin Solid Films 451-452, 420 (2004).

${ }^{5}$ A. M. Gabor, J. R. Tuttle, M. H. Bode, A. Franz, A. L. Tennant, M. A. Contreras, R. Noufi, D. G. Jensen, and A. M. Hermann, Sol. Energy Mater. Sol. Cells 41/42, 247 (1996).

${ }^{6}$ T. Dullweber, G. Hanna, W. Shams-Kolahi, A. Schwartzlander, M. A. Contreras, R. Noufi, and H. W. Schock, Thin Solid Films 361-362, 478 (2000).

${ }^{7}$ M. Gloeckler and J. R. Sites, J. Phys. Chem. Solids 66, 1891 (2005).

${ }^{8}$ S. Schleusser, U. Zimmermann, T. Waetjen, K. Leifer, and M. Edoff, Sol. Energy Mater. Sol. Cells 95, 721 (2011).

${ }^{9}$ M. Troviano and K. Taretto, Sol. Energy Mater. Sol. Cells 95, 821 (2011).

${ }^{10}$ L. J. V. Ruyven and F. E. Williams, Am. J. Phys. 35, 705 (1967).

${ }^{11}$ M. Topič, F. Smole, and J. Furlan, J. Appl. Phys. 79, 8537 (1996).

${ }^{12}$ D. Abou-Ras, R. Caballero, C.-H. Fischer, C. A. Kaufmann, I. Lauermann, R. Mainz, H. Mönig, A. Schöpke, C. Stephan, C. Streeck, S. Schorr, A. Eicke, M. Döbeli, B. Gade, J. Hinrichs, T. Nunney, H. Dijkstra, V. Hoffmann, D. Klemm, V. Efimova, A. Bergmaier, G. Dollinger, T. Wirth, W. Unger, A. A. Rockett, A. Perez-Rodriguez, J. AlvarezGarcia, V. Izquierdo-Roca, T. Schmid, P.-P. Choi, M. Müller, F. Bertram, J. Christen, H. Khatri, R. W. Collins, S. Marsillac, and I. Kötschau, Microsc. Microanal. 17, 728 (2011).

${ }^{13}$ C. L. Perkins, B. Egaas, I. Repins, and B. To, Appl. Surf. Sci. 257, 878 (2010).

${ }^{14}$ C. A. Kaufmann, R. Caballero, T. Unold, H. Mönig, R. Hesse, R. Klenk, and H.-W. Schock, 23rd European Photovoltaic Solar Energy Conference Valencia, Spain, 2170 (2008).

${ }^{15}$ T. Yagioka and T. Nakada, Appl. Phys. Express 2, 072201 (2009).

${ }^{16}$ V. Hoffmann, D. Klemm, V. Efimova, C. Venzago, A. A. Rockett, T. Wirth, T. Nunney, C. A. Kaufmann, and R. Caballero, Elemental Distribution Profiling of Thin Films for Solar Cells in Advanced Characterization Techniques for Thin Film Solar Cells (Wiley-VCH, Weinheim, Germany, 2011), pp. 411-448. 
${ }^{17}$ A. Niemegeers, M. Burgelman, R. Herberholz, U. Rau, D. Hariskos, and H.-W. Schock, Prog. Photovoltaics 6, 407 (1998).

${ }^{18} \mathrm{R}$. Tertian and F. Claisse, Principles of Quantitative X-Ray Fluorescence Analysis (Heyden, Philadelphia, 1982), pp. 56-69.

${ }^{19}$ H. Mönig, I. Lauermann, A. Grimm, C. Camus, C. Kaufmann, P. Pistor, C. Jung, T. Kropp, M. Lux-Steiner, and C.-H. Fischer, Appl. Surf. Sci. 255, 2474 (2008)

${ }^{20}$ H. Mönig, C.-H. Fischer, A. Grimm, B. Johnson, C. Kaufmann, R. Caballero, I. Lauermann, and M. Lux-Steiner, J. Appl. Phys. 107, 113540 (2010).

${ }^{21}$ I. M. Kötschau, Ph.D. thesis, Universität Stuttgart, 2003.

${ }^{22}$ B. Henke, E. Gullikson, and J. Davis, At. Data Nucl. Data Tables 54, 181 (1993).

${ }^{23}$ American Society for Testing and Materials (ASTM), Standard E 673-98, Annual Book of ASTM Standards (ASTM, West Conshohocken, Pennsylvania, 2001), Vol. 3.06, p. 735.

${ }^{24}$ J. Nordgren and J. Guo, J. Electron Spectrosc. Relat. Phenom. 110-111, 1 (2000).

${ }^{25}$ D. Liao and A. Rockett, Appl. Phys. Lett. 82, 2829 (2003).

${ }^{26}$ D. Liao and A. Rockett, J. Appl. Phys. 91, 1978 (2002).

${ }^{27}$ H. Mönig, C.-H. Fischer, R. Caballero, C. Kaufmann, N. Allsop, M. Gorgoi, R. Klenk, H.-W. Schock, S. Lehmann, M. Lux-Steiner, and I. Lauermann, Acta Mater. 57, 3645 (2009).

${ }^{28}$ J. Jaffe and A. Zunger, Phys. Rev. B 64, 241304(1) (2001).
${ }^{29}$ M. Powalla, A. Eicke, K. Pross, and B. Dimmler, in Proceedings of $2 n d$ World Conference on Photovoltaic Solar Energy Conversion, Vienna, Austria (European Commission, Joint Research Center, Ispra, Italy, 1998), p. 1129.

${ }^{30}$ C. Kaufmann, T. Unold, D. Abou-Ras, J. Bundesmann, A. Neisser, R. Klenk, R. Scheer, K. Sakurai, and H.-W. Schock, Thin Solid Films 515, 6217 (2007).

${ }^{31}$ A. Gabor, J. Tuttle, D. Albin, M. Contreras, and R. Noufi, Appl. Phys. Lett. 65, 198 (1994).

${ }^{32}$ K. Sakurai, R. Scheer, S. Nakamura, Y. Kimura, T. Baba, C. A. Kaufmann, A. Neisser, S. Ishizuka, A. Yamada, K. Matsubara, K. Iwata, P. Fons, H. Nakanishi, and S. Niki, Sol. Energy Mater. Sol. Cells 90, 3377 (2006).

${ }^{33}$ R. Klenk, T. Walter, H.-W. Schock, and D. Cahen, Adv. Mater. 5, 114 (1993).

${ }^{34}$ R. Caballero, C. A. Kaufmann, T. Rissom, A. Eicke, P. Manganiello, and H.-W. Schock, 37th IEEE PVSC, Seattle, USA, (2011).

${ }^{35}$ C. Kaufmann, R. Caballero, T. Unold, R. Hesse, R. Klenk, S. Schorr, M. Nichterwitz, and H.-W. Schock, Sol. Energy Mater. Sol. Cells 93, 859 (2009).

${ }^{36}$ R. Caballero, C. A. Kaufmann, V. Efimova, T. Rissom, V. Hoffmann, and H.-W. Schock, "Investigation of $\mathrm{Cu}(\mathrm{In}, \mathrm{Ga}) \mathrm{Se}_{2}$ thin-film formation during the multi-stage co-evaporation process," Prog. Photovoltaics, (to be published).

${ }^{37}$ D. Rudmann, D. Brémaud, A. F. da Cunha, G. Bilger, A. Strohm, M. Kaelin, H. Zogg, and A. N. Tiwari, Thin Solid films 480-481, 55 (2005). 